\title{
A Framework for the Evaluation of CASE Tool Learnability in Educational Environments
}

\author{
Mali Senapathi \\ Auckland University of Technology, Auckland, New Zealand
}

\author{
mali.senapathi@aut.ac.nz
}

\begin{abstract}
The aim of the research is to derive a framework for the evaluation of Computer Aided Software Engineering (CASE) tool learnability in educational environments. Drawing from the literature of Human Computer Interaction and educational research, a framework for evaluating CASE tool learnability in educational environments is derived. The two main differences between this framework and existing evaluation frameworks is that 1 ) it is specific to educational environments and 2) it recognizes the significance of contextual factors such as learning environment and teaching and learning methodologies in evaluating learnability. The framework is oriented towards learnability and is customisable. It helps to define the important issues related to CASE tool learnability, and allows conclusions to be drawn about all influential factors on learning in the given context.
\end{abstract}

A detailed case study describes the application of the framework to evaluate the learnability of Rational Rose, a CASE tool used in an undergraduate Systems Analysis and Design course.

Keywords: framework, CASE, learnability, UML

\section{Introduction}

The use of Computer Aided Software Engineering (CASE) tools in the industry has shown improvements in productivity and system delivery rates (Banker \& Kauffman, 1991; Finlay \& Mitchell, 1994). The benefits of using CASE tools in education such as its role as a pedagogical instrument for teaching a systems development methodology (Jankowski, 1995; Linder, Steele, \& Dorling, 1994) and its role in enabling students to fit into the contemporary work place much easier and faster (Cifuentes \& Lockwood, 1996; Rajkumar, 1992), are well recognized by the research community. Yet, there is insufficient understanding of the various issues that students confront while learning a CASE tool (Fowler, Armarego, \& Allen, 2001). According to Boloix and Robillard (1998), "CASE tool learnability is a subject that has not received much attention from the research community".

Material published as part of this journal, either on-line or in print, is copyrighted by the publisher of the Journal of Information Technology Education. Permission to make digital or paper copy of part or all of these works for personal or classroom use is granted without fee provided that the copies are not made or distributed for profit or commercial advantage AND that copies 1) bear this notice in full and 2) give the full citation on the first page. It is permissible to abstract these works so long as credit is given. To copy in all other cases or to republish or to post on a server or to redistribute to lists requires specific permission and payment of a fee. Contact Editor@JITE.org to request redistribution permission.
Despite the potential benefits of CASE tools recognized by both the industry and the academia, the rate of adoption by the industry is slow (Holt, 1997). Research cites a number of reasons for this low rate of adoption, which include the difficulty in learning to use the tool (Fowler et al., 2001). The learning curve problem associated with CASE tools is also widely recognized by the academic 
community, who argue that most commercial CASE tools suffer from the problems of a long learning curve and do not cater well to the student learning requirements (Cowling, 1998; Jankowski, 1995).

Other reasons for the low rate of adoption include the shortcomings in the usability of functionality of CASE tools available today (Phillips, Mehandjiska, Griffin, Choi, \& Page ,1998). In order to ensure a general acceptance of any system, it should provide a consistent, robust and usable interface and this is specifically true in the case of CASE tools which usually provide a highly interactive and graphics intensive environment (Phillips et al., 1998). However, not enough research exists that has paid attention to the evaluation of the user interface in CASE tools (Phillips et al., 1998).

While the frameworks that exist for the evaluation of educational software are suitable and relevant for the evaluation of educational technologies such Computer Assisted Learning (CAL) systems (Jones et al., 1999; Squires \& Preece, 1996), the existing evaluative methods and frameworks for CASE tools are mainly suitable for evaluation in industrial environments. The existing frameworks for the evaluation of CASE tools are mainly intended for its evaluation and selection in organizations (Misra, 1990; Mosley, 1992). They specify an exhaustive set of evaluation criteria, and Usability or learnability evaluation is not the single main focus of these frameworks. In general, these frameworks provide insufficient support for the evaluation of CASE tool learnability in educational environments. A new evaluation framework has been proposed to support the learnability assessment of CASE tools in educational environments.

The framework is used to find out the i) effect of contextual factors such as user, task and learning environment on CASE tool learnability and ii) whether the CASE tool allows learners with different characteristics to successfully learn the tool. The framework is specific to educational environments and oriented towards CASE tools and incorporates learnability principles. It is customizable and extensible to allow changes. The framework may be used by researchers to evaluate CASE tool learnability in different educational environments.

The application of the framework to evaluate the learnability of Rational Rose, a CASE tool used in an undergraduate Systems Analysis and Design course, at the University of Auckland, New Zealand is described. It is believed that the results and findings from this research will allow for the experiences to be shared and add value to a better understanding of CASE tool learnability in educational environments.

\section{CASE Tools in Education}

Since Unified Modelling Language (UML) became an OMG (Object Management Group) standard and is generally accepted as the prominent modelling language by the industry, many educational practitioners have started using UML to facilitate in the teaching of object-oriented methodology in their undergraduate software engineering courses (Frosch-Wilke, 2003; Tabrizi, Collins, Ozan, \& Li, 2004). However, more recent research has recognized that UML can be taught effectively only with the support of an appropriate CASE tool (Burton \& Bruhn, 2003; Johnson \& Wilkinson, 2003; Tabrizi et al., 2004).

Some of the important benefits of using CASE tools in teaching Systems Analysis and design courses are, i) its role as a pedagogical instrument in teaching and learning a systems development methodology (Jankowski, 1995; Linder et al., 1994) and ii) to provide support in teaching tools and techniques which are popular in the workplace and putting the students on the forefront of new and leading edge technologies (Costain, 1996; Mynatt \& Leventhal, 1990).

However, the learning curve problem associated with CASE tools is well known. The issues related to the difficulties in learning CASE tools and the perceived complexity of learning CASE 
tools is recognized by educational practitioners, who complain that most commercial CASE tools are not adaptable to the learning requirements of student projects and some of the more comprehensive ones suffer from the problems of a long learning curve (Cowling, 1998). Investigating the contextual factors that effect CASE tool learnability, will provide valuable in sights to a better understanding of the issues that students confront while learning a CASE tool. It will provide an opportunity for educators to adapt their instructional strategies to suit the learning needs of users with different individual characteristics.

\section{Learnability}

Learnability is one of the most important and fundamental attributes of usability, "since most systems need to be easy to learn, and since the first experience most people have with a system is that of learning to use it" (Nielsen, 1993). CASE tool learnability is defined as a measure of the ease with which new users can construct a mental model of the CASE tool, remember it and begin effective interaction (Phillips et al., 1998).

The main underlying premise of this study is that learnability is dependent on the context of use and will depend on the contextual factors in which a tool is used (Bevan \& Macleod, 1994).

\section{Research Design}

The proposed framework (See Figure 1) is adapted from the ISO 9241 usability framework and is mainly based on part 11 of the standard, 'Guidance on usability' where the context of use is defined in terms of the user, the task, the equipment and the environment. It aims to investigate and analyze CASE tool learnability in combination with other contextual factors in real educational settings to answer the following questions:

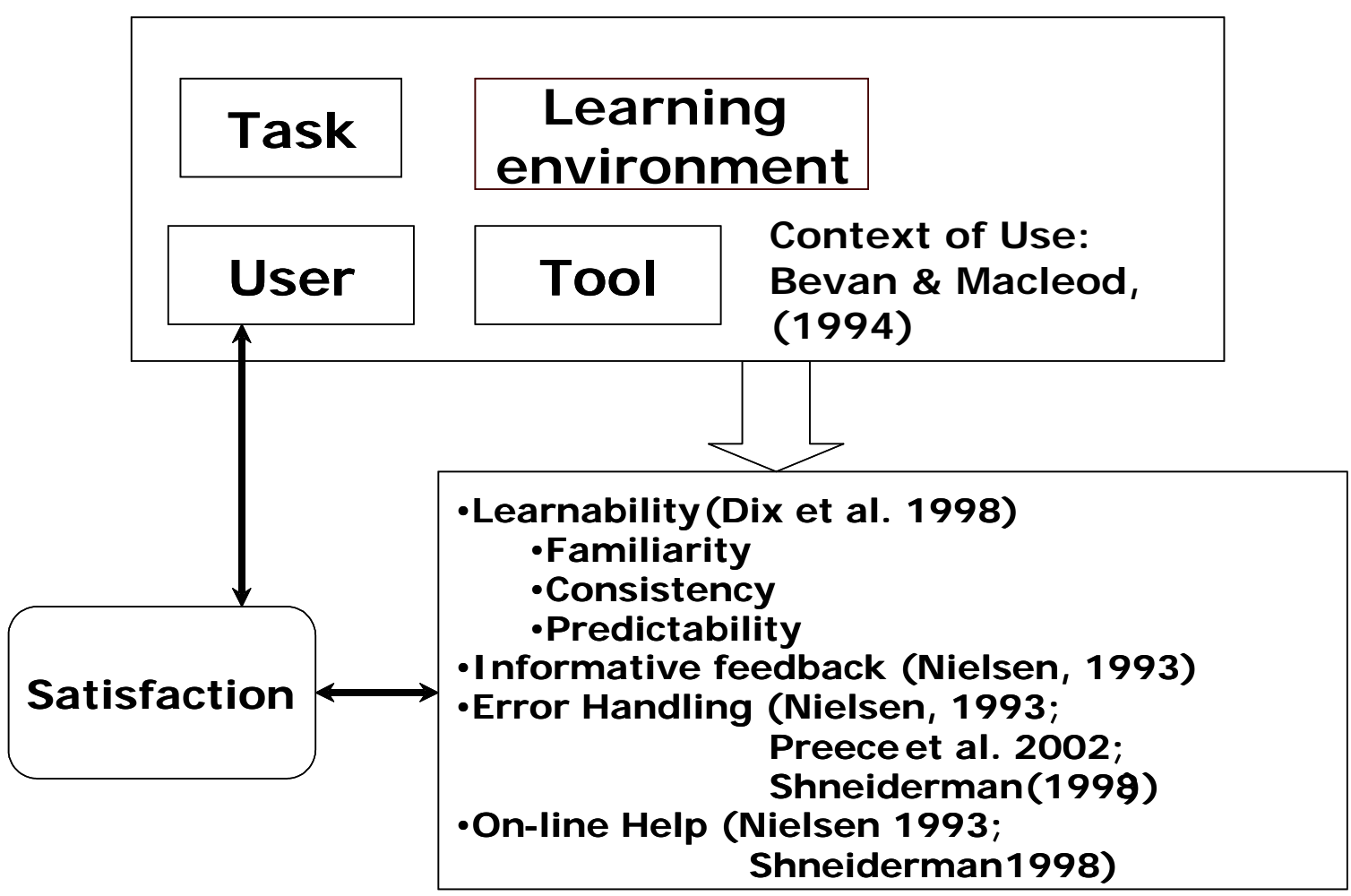

Figure 1: A framework for evaluation of CASE tool learnability 
1. Is learnability dependent on factors such as the context in which the course/tool is taught, background and individual characteristics of learners, and teaching and learning methodologies used, and

2. Does the CASE tool allow learners with different characteristics to successfully learn the tool?

\section{User}

As the knowledge of individual user characteristics such as age, educational level and previous computer experience will enable us to better understand their learning difficulties (Nielsen, 1993), user characteristics such as age, gender, previous level of computer experience (both general and prior experience with CASE tools) are recognized as important characteristics to be included under this category.

\section{Task}

Task analysis is a list of all the things that the users want to carry out using the system, the preconditions required to achieve these goals, the various steps involved and the interdependencies between these steps, and all the various outputs and reports that need to be produced (Nielsen, 1993). In an educational context, all the activities and assessments that mandate the use of a CASE tool are recognized as 'tasks' and the task analysis may include the following:

1. assessment activities (both formative and summative) that mandate the use of the tool,

2. goals of the tutorials and exercises used to support the learning of the tool

3. dependencies, if any, between the tutorials/formative assessments and the output requirements of the summative assessments that mandate the use of the tool.

\section{The learning environment}

Drawing an analogy between the significance of the users' work environment in the usability evaluation of a system in an organization (Nielsen, 1993), the framework recognizes the significance of learning environment in the learnability evaluation of CASE tools in educational environments. The background and context in which the course is delivered should be studied and analyzed. The pedagogical characteristics such as organisation of the teaching process, teaching methods, range of methods and resources used in the teaching of the CASE tool, and learning methodologies used should be studied. An understanding of the course structure will provide us with an understanding of, if how and when the CASE tool is taught will have an effect on learnability; for example, whether the underlying methodology is taught first before the introduction of CASE tool or whether they are taught in parallel in different sessions and does this factor affect learnability.

\section{The tool}

In any usability evaluation study, the focus of attention is usually on a specific item to be evaluated in a given context (Bevan \& Macleod, 1994) and so the last contextual component of the proposed framework is the tool that is to be evaluated, i.e. the CASE tool. Since the users of CASE tools in educational environments are predominantly students who come from varying backgrounds and different characteristics, the chosen CASE should be learnable and provide support for a wide range of different learner characteristics. 


\section{Learnability measures in the study}

Learnability comprises of specific measurable attributes (Dix, Abowd, Beale, \& Finlay, 1998; Nielsen, 1993) and a system's learnability can be effectively evaluated by measuring these attributes in a real-life context. Drawing from the literature, the next section derives and describes the usability principles that support learnability criteria. While the usability principles that directly support learnability (Familiarity, Consistency and Predictability) are adapted from the learnability classification proposed by Dix et al. (1998), the usability characteristics: informative feedback, error-handling and on-line help are added as supplementary factors that might affect learnability

- Ease of learning (learnability) (Nielsen, 1993; Preece, Rogers, \& Sharp, 2002)

$\checkmark$ Familiarity (Dix et al., 1998; Phillips et al., 1998)

$\checkmark$ Consistency (Dix et al., 1998; Preece et al., 2002; Phillips et al., 1998; Shneiderman, 1998,)

$\checkmark \quad$ Predictability (Dix et al., 1998; Phillips et al., 1998)

- Informative feedback (Nielsen 1993)

- $\quad$ Error handling (Dix et al. 1998; Nielsen, 1993; Preece et al., 2002; Shneiderman, 1998)

- On-line Help (Nielsen, 1993; Shneiderman, 1998)

\section{Ease of learning}

As 'ease of learning' refers to the novice user's experience on the initial part of the learning curve while trying to learn a new system (Nielsen, 1993), it is the most important learnability criteria to be evaluated on student learners, who may be categorized as novice users.

CASE tool Learnability is a measure of the ease with which new users can construct a mental model of the CASE tool, and begin effective interaction (Phillips et al., 1998), and has the subcategories of familiarity, consistency and predictability (Dix et al., 1998; Phillips et al., 1998).

\section{Familiarity}

The familiarity of an interactive system measures the correlation between the user's existing knowledge/ previous experience and the knowledge required for effective interaction (Dix et al., 1998). In the context of CASE tools, it is the extent to which a user's prior knowledge can be applied in learning to use the CASE tool, which includes knowledge of other CASE tools, the underlying methodology, and computer-based systems in general (Phillips et al., 1998).

\section{Consistency}

Consistency is the most widely mentioned usability principle in the literature (Dix et al. 1998). Consistent interfaces are easier to learn and use (Preece et al., 2002), which in turn assists the users in gaining more confidence in using the system and encourages them to try out exploratory learning strategies (Nielsen, 1993). In CASE tools, it refers to the uniformity of the behaviour of the CASE tool in similar situations or in performing similar task objectives (Phillips et al., 1998).

\section{Predictability}

Predictability refers to the ease with which a user can determine the result of his future interactions with the interface based on the past interaction history (Dix et al., 1998; Phillips et al., 1998). It is a user-centered concept which refers to the deterministic behaviour of the system from the user's perspective (Dix et al., 1998). 


\section{Informative feedback}

Effective feedback, which refers to providing informative, positive and continuous feedback about what it is doing and how it is interpreting the user's input, facilitates the activities of the learners (Galitz, 1996; Nielsen, 1993).According to Norman (1999), "the presence of feedback can dramatically affect the usability and understandability of a system”.

\section{Error handling}

Superior error messages which are more specific, positive in tone, easy to understand and constructive (telling the user how to fix the problem) may lead to lower error rates and increased subjective satisfaction (Shneiderman, 1998). Interfaces that permit the easy reversal of actions facilitates in the user's learning process (Dix et al., 1998; Shneiderman, 1998).

\section{Online help}

As users require a substantial amount of support when they are learning a new system (Preece, 1993), online information has the potential for getting users the precise information they need faster, especially, when they are desperately in need for immediate help (Nielsen, 1993).

\section{Subjective satisfaction}

Subjective satisfaction or user acceptance of a system is considered as a critical measure of a system or tool's success (Chin, Diehl, \& Norman, 1988), where the measures of satisfaction usually relate to specific features of a system and describe the perceived usability of the system by its users (Bevan \& Macleod, 1994). Since the main aim of this study is to develop a framework to evaluate CASE tool learnability by studying the effect of all contextual factors on learning, it was decided to use the satisfaction of the learners as a direct measure to evaluate whether a CASE tool is learnable in a particular context.

\section{Designing a Learnability Questionnaire}

A questionnaire to measure the user's subjective rating of the learnability features of a CASE tool was developed, and is expected to provide a useful indication of the user's subjective satisfaction and perception of learnability. Existing validated questionnaires such as the Questionnaire for User Interface Satisfaction (QUIS), Software Usability Measurement Inventory (SUMI) and ISOMETRICS are valuable tools. However, the usability measures used in these questionnaires are too general to investigate specific learnability features of CASE tools.

Consequently, many questionnaire items relevant to learnability were chosen from these existing questionnaires and some additional questions were added. The learnability questionnaire consists of both closed-ended and open-ended questions and contains:

1. a demographic questionnaire, which includes age, gender, previous experience with computer: both general level of computer experience and specific experience in using other CASE tools

2. a section to measure attitude and motivation,

3. five scales to measure overall user reaction ratings of the system, such as terriblewonderful, frustrating—satisfying, dull—stimulating, difficult—easy and rigid—flexible.

4. a set of questions to measure each of the learnability principles identified in the framework.

Each of these sections have related questions, where each item is rated on a scale from 1 to 5 with $1=$ "predominantly disgree" and 5 = "predominantly agree". Each section also contains additional 
space allowing the rater to make comments about each section and there is also an "Other information" section which asks students to rate and comment upon the resources that were most useful in their learning of the CASE tool and any other comments concerning their learning of the CASE tool.

\section{Research Method}

Observations and questionnaires were identified as the two main data collection methods. The observations were to record details such as the teaching and learning methodologies used in teaching the CASE tool. The information obtained to be analyzed in relation to other data such as the course assessments and the level of emphasis of CASE tool usage in the course.

The learnability questionnaire to be administered at the end of the semester/term, when students have completed all their course work that mandate the use of the CASE tool. Before administering the questionnaires, it was determined that the questionnaires should take participants no more than 15 minutes to complete.

\section{Conducting the study}

The study was conducted at the University of Auckland, New Zealand. The participants were undergraduate students enrolled in an undergraduate (Bachelor of Commerce, IS Major) degree programme. The author met the participants at the beginning of the semester in Semester 2, 2004, at mutually agreed upon times. The information about the research was explained to the participants and date and times for administering the questionnaires were arranged based upon the consent of the participants.

The course chosen for this study was an introductory course on Systems Analysis and Design, and is usually taken in the second year of the undergraduate degree programme and constitutes one quarter of a full semester's study. It was designed to provide an introduction to fundamental concepts and techniques of information systems analysis and design, using object-oriented analysis and design methods and the Unified Modelling Language (UML) notation.

\section{The learning environment}

There were 105 students enrolled in the course in Semester 2, 2004. Students were timetabled for five hours of contact per week ( 3 one-hour lectures and 1 two-hour tutorial). The course itself was delivered using two main methods: 3 one-hour lecture sessions per week taken by qualified and experienced lecturers and one two-hour laboratory session per week (approximately 25 students in each session) conducted by either the Masters students within the department or by other suitably qualified and experienced candidates.

The students were divided into groups of 25 each for the tutorial sessions. The main aim of these sessions was to demonstrate the concepts taught in the lecture sessions using several examples and case studies, with the aid of appropriate CASE tools. The laboratory was well equipped with all teaching and learning equipment, including individual PCs for every student. The laboratory had the required software and resources (access to online resources such as exercises, case studies, suggested solutions etc) which enabled students to keep pace with the demonstrations while trying to use and learn the tool. Students were given the opportunity to use and learn the CASE tools during these weekly lab tutorial sessions. Students mainly worked on an individual basis, which enabled better interaction between the individual student and the tool.

Though the choice of the CASE tools was not mandated, all students chose to use Rational Rose, as the use of this tool was directly supported in the tutorial sessions. The author attended and observed a few of these laboratory sessions, mainly when Rational Rose was used to demonstrate creation of UML diagrams such as Use Case and Activity Diagrams. 
The laboratory sessions started with a revision of the previous class, and continued with a detailed demonstration of the topic scheduled for that session. For example, a session on developing activity diagrams discussed the following: i) description of activity diagram components, such as Start and Activity state, Decision point, Synchronisation bar, Transition and End state and ii) principles to apply while drawing activity diagrams, such as naming activities, drawing synchronisation bars and when to use decision points etc.

The tutor demonstrated the creation of Activity diagrams with Rational Rose using appropriate examples. Out of the scheduled two hours, this demonstration took approximately one hour. In the next one-hour, students were given an opportunity to apply these concepts using Rational Rose on similar problems/ case studies. After the one-hour demonstration, it was observed that most students were comfortable in getting started with the CASE tool. During this period, the tutor facilitated their learning process by providing individual support to students and answering questions related to the use and functioning of the CASE tool. Queries related to the example problems were also clarified. The solutions to some of these examples were also discussed at the end of the session.

\section{Task}

The assessment tasks that mandated the use of CASE tools equaled approximately $30 \%$ of the overall course assessments. The important UML diagrams that students were required to learn included Use Case diagrams, Activity diagrams and Class diagrams. A detailed marking guide further differentiated clearly between the content and technical coverage required in the creation of these diagrams. For example, if the content requirements emphasized the extent to which the Use Case modelling principles have been applied to reflect the business requirements, the technical requirements focused on how appropriately the Use Case diagram constructs have been used in both the overview and detailed diagrams, such as appropriate labels reflecting the use case from the systems perspective and appropriate associations between use cases. In general, the tasks required students to apply their understanding of the goals and processes of object-oriented Systems Analysis and Design using UML. The subset of the UML diagrams such as Use Case diagram, Activity diagrams and Class diagrams, required for the successful completion of the tasks were identified.

\section{User characteris- tics}

Out of the 105 students enrolled, 40 students (25 male and 15 female), most of whom fell in the age group of 18-25 (39 students were in the group 18-25 and only one student was in the over 40 group) agreed to participate. To provide an overview of the ratings of the learnability section for the questionnaire, the profile of mean ratings for each component ques-

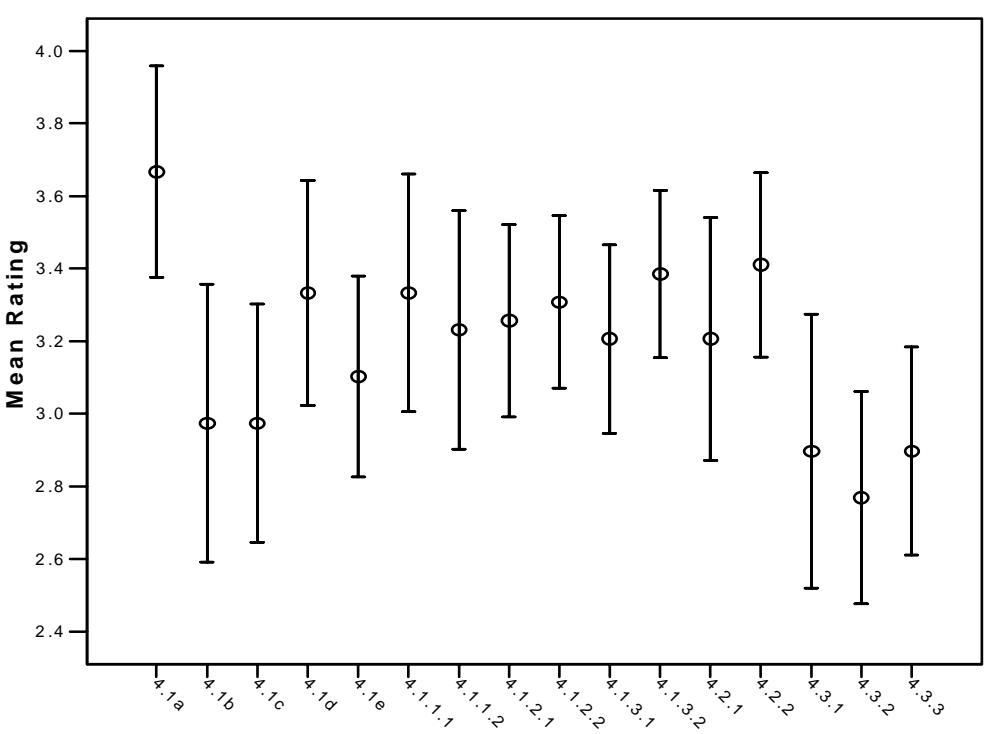

Figure 2: Profile of Mean ratings 
tion and their 95\% confidence interval is shown in Figure 2.

A one-way Chi-square test of homogeneity was conducted on the responses for each closedended item in the questionnaire. The nature of the significant results is shown in Table 1, where a significant p-value indicates that the responses are not equally distributed across the items. The mean and the standard deviation for each Likert-type question are also listed.

Table 1: Closed-ended questions and responses

\begin{tabular}{|c|c|c|c|c|}
\hline $\begin{array}{l}\text { Learnability Catego- } \\
\text { ries }\end{array}$ & & Mean & $\begin{array}{l}\text { Standard } \\
\text { Deviation }\end{array}$ & $\begin{array}{l}\text { p- value } \\
\text { (Chi- } \\
\text { Square) }\end{array}$ \\
\hline \multirow[t]{5}{*}{ Ease of learning } & $\begin{array}{l}\text { 4.1a) It was easy for me to get started and } \\
\text { to learn how to use the tool. }\end{array}$ & 3.68 & .80 & $.001^{* *}$ \\
\hline & $\begin{array}{l}\text { 4.1b) I was able to use the tool right from } \\
\text { the beginning, without having to ask my } \\
\text { tutors or peers for help. }\end{array}$ & 2.95 & .86 & .112 \\
\hline & $\begin{array}{l}\text { 4.1c) The system encouraged me to try out } \\
\text { new system functions by trial and error. }\end{array}$ & 2.95 & 1.12 & $.002^{* *}$ \\
\hline & $\begin{array}{l}\text { 4.1d) It was easy for me to remember } \\
\text { commands from one session to another. }\end{array}$ & 3.38 & 1.3 & $.002^{* *}$ \\
\hline & $\begin{array}{l}\text { 4.1e) The explanations provided helped } \\
\text { me to become more and more skilled at } \\
\text { using it. }\end{array}$ & 3.15 & .88 & $.002^{* *}$ \\
\hline \multirow[t]{2}{*}{ Familiarity } & $\begin{array}{l}\text { 4.1.1.1) Was your prior knowledge of other } \\
\text { computer-based systems useful in the } \\
\text { learning of the CASE tool? }\end{array}$ & 3.38 & .88 & $.000^{* *}$ \\
\hline & $\begin{array}{l}\text { 4.1.1.2) Was your prior knowledge of other } \\
\text { CASE tools useful in the learning of the } \\
\text { CASE tool? }\end{array}$ & 3.23 & .73 & $.003^{* *}$ \\
\hline \multirow[t]{2}{*}{ Consistency } & $\begin{array}{l}\text { 4.1.2.1) The tool is consistently designed, } \\
\text { thus making it easier for me to do my work }\end{array}$ & 3.30 & .97 & $.000^{* *}$ \\
\hline & $\begin{array}{l}\text { 4.1.2.2) I find that the same function keys } \\
\text { are used throughout the program for the } \\
\text { same functions }\end{array}$ & 3.35 & .66 & $.009^{* *}$ \\
\hline \multirow[t]{2}{*}{ Predictability } & $\begin{array}{l}\text { 4.1.3.1) The tool behaves similarly and } \\
\text { predictably in similar situations. }\end{array}$ & 3.25 & .83 & $.000^{* *}$ \\
\hline & $\begin{array}{l}\text { 4.1.3.2) When executing functions, I get } \\
\text { results that are predictable }\end{array}$ & 3.43 & .87 & $.000^{* *}$ \\
\hline \multirow[t]{2}{*}{ Informative feedback } & 4.2.1) Animated cursors keep you informed & 3.20 & .83 & $.000^{* *}$ \\
\hline & $\begin{array}{l}\text { 4.2.2) Performing an operation leads to a } \\
\text { predictable result }\end{array}$ & 3.40 & .69 & $.000^{* *}$ \\
\hline \multirow[t]{3}{*}{ Error messages } & $\begin{array}{l}\text { 4.3.1) If I make a mistake while performing } \\
\text { a task, I can easily undo the last operation }\end{array}$ & 2.93 & .93 & $.02^{*}$ \\
\hline & 4.3.2) Error messages clarify the problem & 2.80 & .89 & $.017^{*}$ \\
\hline & $\begin{array}{l}\text { 4.3.3) I perceive the error messages as } \\
\text { helpful }\end{array}$ & 2.90 & 1.03 & $.000^{* *}$ \\
\hline
\end{tabular}

* Significant at the 0.05 level; ** Significant at the 0.01 level 


\section{Reliability}

The reliability of the questionnaire which relates to evoking consistent responses is directly related to the number of items, and a higher reliability can be achieved if there are larger number of items in the questionnaire (Chin et al.,1988). The overall reliability of the learnability section of the questionnaire using Cronbach’s alpha was .806.

\section{Highest and lowest rated questions}

The highest rated questions were 4.1a; 4.1.3.2 and 4.2.2 (refer to Table 1), which related to ease of learning, predictability and informative feedback. These findings are consistent with the findings from a recent study, where Rational Rose scored high on all the three learnability features (Consistency, Familiarity and Predictability) (Phillips et al., 1998). This indicates that students have generally agreed that Rational Rose had good learnability with most of the p-values significant at the 0.01 level and means greater than 3 with p-values less than 0.05 (these items are bolded in table 1). The question 4.1a -'It was easy for me to get started and to learn how to use the tool' was evaluated very favorably, which is recognized as the most desirable feature required for novice users (Nielsen, 1993). This is also the feature that is most likely to be effected by the learning environment and the methodologies used in teaching the CASE tool. Interestingly, all the three lower rated questions belonged to the Error Handling category.

\section{Effect of User Characteristics on Learnability}

Next, the study explored the effects of five user characteristics (Gender, General level of Computer Experience, Previous Experience with CASE tools, No of hours spent per week with the CASE tool and Attitude and Motivation) on users' rating of different learnability categories. Correlation, MANOVA and ANOVA tests were used to conduct statistical analyses on subjects' ratings.

First, a correlation test was performed on the dependent variables (learnability categories) to determine whether or not they are correlated. The results of the correlational analyses presented in Table 2 show that 11 out of the 21 correlations were statistically significant and were greater than or equal to .35, which can be considered as correlations of a moderate level.

The correlations of Informative feedback and Error Messages with the other learnability measures tended to be lower and not significant. In general, the results suggest that if students say that they are satisfied in one learnability aspect, they tend to state that they are satisified in other aspects (including their overall reactions to the CASE tool) except for Informative feedback and Error Messages.

Next, MANOVA tests were run to test the null hypotheses that the user characteristics had no effects on learnability. However, it was decided to run MANOVA for all dependent variables except Informative feedback and Error Messages, as these did not show any correlations with any other variable. This is because MANOVA requires that dependent variables be moderately correlated. 
Table 2: Correlation results

\begin{tabular}{|c|c|c|c|c|c|c|c|c|}
\hline \multicolumn{9}{|c|}{ Correlations } \\
\hline & & $\begin{array}{l}\text { Ease of } \\
\text { learning }\end{array}$ & Familiarity & Consistency & Predictability & $\begin{array}{l}\text { Informative } \\
\text { feedback }\end{array}$ & $\begin{array}{c}\text { Error } \\
\text { Messages }\end{array}$ & $\begin{array}{c}\text { Overall } \\
\text { Reactions }\end{array}$ \\
\hline \multirow{3}{*}{$\begin{array}{l}\text { Ease of } \\
\text { learning }\end{array}$} & Pearson Correlation & 1 & $.451^{\text {ж }}$ & $.472^{\star \prime}$ & .264 & .112 & .277 & $.368^{\star}$ \\
\hline & Sig. (2-tailed) & & .004 & .002 & .099 & .493 & .083 & .027 \\
\hline & $\mathrm{N}$ & 40 & 40 & 40 & 40 & 40 & 40 & 36 \\
\hline \multirow[t]{3}{*}{ Familiarity } & Pearson Correlation & $.451^{*}$ & 1 & $.781^{\star}$ & $.420 *$ & $\begin{array}{l}.024 \\
\end{array}$ & .138 & $.444^{\star}$ \\
\hline & Sig. (2-tailed) & .004 & & .000 & .007 & .881 & .395 & .007 \\
\hline & $\mathrm{N}$ & 40 & 40 & 40 & 40 & 40 & 40 & 36 \\
\hline \multirow[t]{3}{*}{ Consistency } & Pearson Correlation & $.472^{\star}$ & $.781^{\star}$ & 1 & $.545 *$ & -.050 & .119 & $.527^{*}$ \\
\hline & Sig. (2-tailed) & .002 & .000 & & .000 & .758 & .466 & .001 \\
\hline & $\mathrm{N}$ & 40 & 40 & 40 & 40 & 40 & 40 & 36 \\
\hline \multirow[t]{3}{*}{ Predictability } & Pearson Correlation & .264 & $.420^{\star \prime}$ & $.545^{\star}$ & 1 & .119 & $.350^{*}$ & $.345^{\star}$ \\
\hline & Sig. (2-tailed) & .099 & .007 & .000 & & .466 & .027 & .040 \\
\hline & $\mathrm{N}$ & 40 & 40 & 40 & 40 & 40 & 40 & 36 \\
\hline \multirow{3}{*}{$\begin{array}{l}\text { Informative } \\
\text { feedback }\end{array}$} & Pearson Correlation & .112 & -.024 & -.050 & .119 & 1 & .304 & .096 \\
\hline & Sig. (2-tailed) & .493 & .881 & .758 & .466 & & . 056 & .576 \\
\hline & $\mathrm{N}$ & 40 & 40 & 40 & 40 & 40 & 40 & 36 \\
\hline \multirow{3}{*}{$\begin{array}{l}\text { Error } \\
\text { Messages }\end{array}$} & Pearson Correlation & .277 & .138 & .119 & $.350^{*}$ & .304 & 1 & $.360^{\star}$ \\
\hline & Sig. (2-tailed) & .083 & .395 & .466 & .027 & .056 & & .031 \\
\hline & $\mathrm{N}$ & 40 & 40 & 40 & 40 & 40 & 40 & 36 \\
\hline \multirow{3}{*}{$\begin{array}{l}\text { Overall } \\
\text { Reactions }\end{array}$} & Pearson Correlation & $.368^{\star}$ & $.444^{\star}$ & $.527^{\star}$ & $.345^{*}$ & .096 & $.360^{*}$ & 1 \\
\hline & Sig. (2-tailed) & .027 & .007 & .001 & .040 & .576 & .031 & \\
\hline & $\mathrm{N}$ & 36 & 36 & 36 & 36 & 36 & 36 & 36 \\
\hline
\end{tabular}

Each characteristic is a category to identify subjects. For each category, students were classified into different groups:

Gender: male, female

General level of Computer Experience: low, moderately low, moderately high and high

Previous Experience with CASE tools: none/less than one month, one month or more, but less than six months, six months to one year, and more than one year

No of hours spent per week: less than one hour, one to less than 4 hours, 4 to less than 10 hours and over 10 hours.

Attitude and Motivation: A set of questions was used to measure this. Students were asked to rate each question on a scale of 1-5 scale ranging from predominantly disagree to predominantly agree.

The results of MANOVA tests showed that among the five characteristics, three had significant effects on learnability. The test results are summarized in Table 3.

Table 3: Summary of MANOVA tests

\begin{tabular}{|l|l|l|}
\hline User Characteristics & $\begin{array}{l}\text { Tests of H0: no significant } \\
\text { differences between groups }\end{array}$ & Results of MANOVA \\
\hline Gender & Accepted & $\mathrm{F}(4,35)=1.55, \mathrm{p}=0.2$ \\
\hline Computer Experience & Rejected & $\mathrm{F}(4,35)=3.58, \mathrm{p}<.05$ \\
\hline $\begin{array}{l}\text { Previous Experience with } \\
\text { CASE tools }\end{array}$ & Rejected & $\mathrm{F}(4,35)=3.62, \mathrm{p}<.02$ \\
\hline Number of hours spent & Accepted & $\mathrm{F}(4,30)=0.76, \mathrm{p}=.56$ \\
\hline Attitude and Motivation & Rejected & $\mathrm{F}(16,23)=3.34, \mathrm{p}<.005$ \\
\hline
\end{tabular}


General level of computer experience, prior experience with CASE tools and the user's attitude and motivation each had a significant effect on learnability ratings and the null hypotheses about these three characteristics were rejected. The main effect found on computer experience was significant, $\mathrm{F}(4,35)=3.58, \mathrm{p}<.05$, meaning there was a significant difference among the different groups of students in their ratings.

A significant, $F(4,35)=3.62, p<.02$, difference was found on the characteristic of Previous Experience with CASE tools, which suggest that students from different groups differed significantly in their ratings. Significant differences was also found on attitude and motivation, F (16, $23)=3.34, p<.005$, meaning that students with varying levels of attitude and motivation, differed significantly in their ratings. However, the other two characteristics (Gender and Number of hours spent) did not return any significant difference between the different groups for each characteristic and the learnability ratings, and hence the null hypotheses were accepted.

\section{Differences in ratings across subgroups}

For each of the user characteristics where the F test was significant, follow-up ANOVAs were conducted, one for each dependent variable.

\section{General level of computer experience}

The students' general level of computer experience was measured by the question, "How would you describe your general level of computer experience?” and had four choices: Low (I have used only one or two software applications), Moderately low (I have learned and used between two and five different software applications), Moderately high (I have learned and used more than five different software applications but have no programming skills), and High (I have learned and used more than five different software applications and have some programming skills)

Levene's test was used to check the assumption that the variances of the four groups for computer experience groups are equal; i.e., not significantly different. The assumption was not violated as the tests were not significant for all the groups except for Error handling.

A one-way analysis of variance on Computer Experience and the mean ratings for the section "Overall reactions” ("terrible/wonderful”, "frustrating/satisfying”, "dull/stimulating”, "difficult/easy”, "rigid/flexible”) did not return any significant results. A one-way analysis of variance was also performed on Computer Experience and the mean ratings for all categories and subcategories in the "Learnability" section, which returned significant results for the sections "Ease of learning" $(F(3,36)=4.203, p=0.012)$ and "Consistency" $(F(3,36)=3.527, p=0.024)$. The ANOVA table for these results (both significant and borderline differences) is shown in Table 4. 
Table 4: ANOVA results- Computer Experience

\begin{tabular}{|c|c|c|c|c|c|c|}
\hline & & $\begin{array}{l}\text { Sum of } \\
\text { Squares }\end{array}$ & df & Mean Square & $\mathrm{F}$ & Sig. \\
\hline \multirow{3}{*}{$\begin{array}{l}\text { Overall } \\
\text { Reactions }\end{array}$} & Between Groups & .826 & 3 & .275 & 1.320 & .285 \\
\hline & Within Groups & 6.676 & 32 & .209 & & \\
\hline & Total & 7.502 & 35 & & & \\
\hline \multirow{3}{*}{$\begin{array}{l}\text { Ease of } \\
\text { learning }\end{array}$} & Between Groups & 4.956 & 3 & 1.652 & 4.203 & .012 \\
\hline & Within Groups & 14.148 & 36 & .393 & & \\
\hline & Total & 19.104 & 39 & & & \\
\hline \multirow[t]{3}{*}{ Familiarity } & Between Groups & 4.117 & 3 & 1.372 & 1.889 & .149 \\
\hline & Within Groups & 26.158 & 36 & .727 & & \\
\hline & Total & 30.275 & 39 & & & \\
\hline \multirow[t]{3}{*}{ Consistency } & Between Groups & 5.059 & 3 & 1.686 & 3.527 & .024 \\
\hline & Within Groups & 17.216 & 36 & .478 & & \\
\hline & Total & 22.275 & 39 & & & \\
\hline \multirow[t]{3}{*}{ Predictability } & Between Groups & 2.124 & 3 & .708 & 2.028 & .127 \\
\hline & Within Groups & 12.570 & 36 & .349 & & \\
\hline & Total & 14.694 & 39 & & & \\
\hline \multirow{3}{*}{$\begin{array}{l}\text { Informative } \\
\text { feedback }\end{array}$} & Between Groups & 1.287 & 3 & .429 & .699 & .559 \\
\hline & Within Groups & 22.113 & 36 & .614 & & \\
\hline & Total & 23.400 & 39 & & & \\
\hline \multirow{3}{*}{$\begin{array}{l}\text { Error } \\
\text { Handling }\end{array}$} & Between Groups & 1.537 & 3 & .512 & .792 & .506 \\
\hline & Within Groups & 23.283 & 36 & .647 & & \\
\hline & Total & 24.819 & 39 & & & \\
\hline
\end{tabular}

As the Ease of learning and Consistency dependent variables are statistically significant and there are four levels or values of Computer Experience, post hoc multiple comparisons were made to see which pair means are different. These results are summarized in Table 5.

Table 5: Results of post-hoc tests on learnability for Computer Experience

\begin{tabular}{|l|l|l|l|l|}
\hline $\begin{array}{l}\text { Computer Experience } \\
\text { Groups }\end{array}$ & $\begin{array}{l}\text { Ease of } \\
\text { learning }\end{array}$ & Familiarity & Consistency & Predictability \\
\hline low and moderately low & Yes & & & \\
\hline low and moderately high & Yes & & & \\
\hline Low and high & Yes & Yes & Yes & \\
\hline High and moderately high & & & Yes & Yes \\
\hline
\end{tabular}

Note: A Yes means a difference, significant at $\alpha=0.05$ levels, was found between the two groups.

These results indicate that students who had 'low' level of computer experience rated 'Ease of learning' lower than students who had 'moderately low' and students who had 'moderately high' level of experience. They also rated lower than students who had 'high' level of computer experience. Similarly, students who had 'low' level of computer experience rated 'Familiarity' and 'Consistency' lower than students who had 'high' level of computer experience. Students who had 'moderately high' level of computer experience rated 'Consistency' and 'Predictability' lower than students who had 'high' level of computer experience. The group mean values for Computer experience on the different learnability categories are shown in the Table 6 . 
Table 6: Group Mean Values for Computer Experience on learnability categories

\begin{tabular}{|l|l|l|l|l|l|}
\hline \multicolumn{7}{|l|}{ Group Mean values } \\
\hline Computer Exp. & $\begin{array}{l}\text { Ease of } \\
\text { learning }\end{array}$ & Familiarity & Consistency & Predictability & $\begin{array}{l}\text { Overall } \\
\text { reactions }\end{array}$ \\
\hline low & 2.0 & 2.3 & 2.5 & 3.2 & 3.3 \\
\hline Moderately low & 3.4 & 3.3 & 3.0 & 3.1 & 2.9 \\
\hline Moderately High & 3.2 & 3.0 & 2.8 & 2.8 & 2.9 \\
\hline High & 3.4 & 3.5 & 3.5 & 3.5 & 3.3 \\
\hline
\end{tabular}

Significant differences were not found between the students' level of computer experience and their rating on error messages, which suggests that all students, irrespective of their previous level of general computer experience, found that the interface did not perform well in handling error messages.

\section{Previous experience with CASE tool}

The students previous experience with CASE tools was measured by the question "Before beginning to use the Rational Rose CASE tool, how much experience did you have working with other CASE tools (e.g. VISIO)?” and had four choices: None/less than one month, One month or more, but less than six months, six months to one year and more than one year.

A one-way analysis of variance performed on previous experience and the mean ratings for the section "Overall reactions" did not return any significant results. A one-way analysis of variance was performed on previous experience and the mean ratings for all categories and sub-categories in the "Learnability" section. Significant differences were reported for previous experience on the mean overall rating for the "Ease of learning" $(F(3,36)=4.211, p<0.01)$. Though not significant at the 0.05 levels, the ANOVA in Table 7 shows borderline differences between ratings of students with varying levels of prior experience on most categories of learnability.

\begin{tabular}{|c|c|c|c|c|c|c|}
\hline & & $\begin{array}{l}\text { Sum of } \\
\text { Squares }\end{array}$ & df & Mean Square & $\mathrm{F}$ & Sig. \\
\hline \multirow{3}{*}{$\begin{array}{l}\text { Ease of } \\
\text { learning }\end{array}$} & Between Groups & 4.963 & 3 & 1.654 & 4.211 & .012 \\
\hline & Within Groups & 14.141 & 36 & .393 & & \\
\hline & Total & 19.104 & 39 & & & \\
\hline \multirow[t]{3}{*}{ Familiarity } & Between Groups & 5.087 & 3 & 1.696 & 2.424 & .082 \\
\hline & Within Groups & 25.188 & 36 & .700 & & \\
\hline & Total & 30.275 & 39 & & & \\
\hline \multirow[t]{3}{*}{ Consistency } & Between Groups & 3.621 & 3 & 1.207 & 2.329 & .091 \\
\hline & Within Groups & 18.654 & 36 & .518 & & \\
\hline & Total & 22.275 & 39 & & & \\
\hline \multirow[t]{3}{*}{ Predictability } & Between Groups & 2.391 & 3 & .797 & 2.332 & .090 \\
\hline & Within Groups & 12.303 & 36 & .342 & & \\
\hline & Total & 14.694 & 39 & & & \\
\hline
\end{tabular}


Post hoc comparison tests showed that the mean rating of students' who had six months to oneyear experience with CASE tools was higher than all the other groups. It also indicated that students who had no prior experience with CASE tools rated both 'Ease of learning' and 'Predictability' lower than students who had at least 'one month to six months' of experience. Also, students who had no prior experience with CASE tools rated 'Ease of learning', 'Familiarity' and 'Consistency' lower than students who had at least 'six months to one year' of prior experience. These results are summarized in Table 8. The group mean values for Previous experience with CASE tools on the different learnability categories are shown in Table 9.

Table 8: Results of ANOVA and Tukey test on learnability for Previous Experience with CASE tools

\begin{tabular}{|l|l|l|l|l|}
\hline $\begin{array}{l}\text { Previous Experience } \\
\text { Groups }\end{array}$ & $\begin{array}{l}\text { Ease of } \\
\text { learning }\end{array}$ & Familiarity & Consistency & Predictability \\
\hline $\begin{array}{l}\text { None/Less than one } \\
\text { month and one month } \\
\text { to six months }\end{array}$ & Yes & & & Yes \\
\hline $\begin{array}{l}\text { None/Less than one } \\
\text { month and six } \\
\text { months to one year }\end{array}$ & Yes & Yes & Yes & \\
\hline
\end{tabular}

Note: $\underline{A \text { Yes means a difference, significant at } \alpha=0.05 \text { levels, was found between the two groups. }}$

Table 9: Group Mean values for Previous Experience and learnability categories

\begin{tabular}{|l|l|l|l|l|l|}
\hline \multicolumn{7}{|l|}{ Group Mean values } \\
\hline $\begin{array}{l}\text { Previous Experi- } \\
\text { ence with CASE } \\
\text { tools }\end{array}$ & $\begin{array}{l}\text { Ease of } \\
\text { learning }\end{array}$ & Familiarity & Consistency & Predictability & $\begin{array}{l}\text { Overall } \\
\text { reactions }\end{array}$ \\
\hline $\begin{array}{l}\text { None/less than } \\
\text { one month }\end{array}$ & 2.9 & 3.1 & 3.1 & 3.2 & 3.1 \\
\hline $\begin{array}{l}\text { One month to six } \\
\text { months }\end{array}$ & 3.7 & 3.7 & 3.6 & 3.8 & 3.4 \\
\hline $\begin{array}{l}\text { Six months to one } \\
\text { year }\end{array}$ & 3.8 & 4.1 & 4.0 & 3.1 & 3.5 \\
\hline $\begin{array}{l}\text { More than one } \\
\text { year }\end{array}$ & 3.4 & 3.0 & 3.3 & 3.0 & 3.3 \\
\hline
\end{tabular}

In general, students who had no previous experience with CASE tools rated lower than students who had 1-6 months and students who had 6 months -1 year experience.

\section{Attitude and Motivation}

Students were asked to describe the way they felt about the use of the CASE tool in their course, by using a set of 6 questions- 3 of these aimed to measure their attitude and 3 to measure motivation. A one-way analysis of variance was conducted on the student's overall mean ratings for Attitude and Motivation and the overall mean ratings for different learnability categories. Only significant differences are reported.

Question 2.1.1 "The use of CASE tool for this course was a good idea”

There were significant differences for Question 2.1.1 on the mean overall rating for "Familiarity" section in the learnability questionnaire $(\mathrm{F}(4,35)=3.445, \mathrm{p}=0.018)$ (Table 10$)$. 
Table 10:

ANOVA- Question 2.1.1 and Familiarity

\begin{tabular}{llrrrrr}
\hline \hline & & Sum of & & & & \\
& & Squares & df & Mean Square & \multicolumn{1}{c}{$\mathrm{F}$} & Sig. \\
\hline Familiarity & Between Groups & 8.553 & 4 & 2.138 & 3.445 & .018 \\
& Within Groups & 21.722 & 35 & .621 & & \\
& Total & 30.275 & 39 & & & \\
\hline \hline
\end{tabular}

Question 2.1.2 "The CASE tool made my work more interesting”

There were significant differences for Question 2.1.2 on the mean overall rating for the categories "Ease of learning” $(F(4,35)=3.943, p=0.01)$, “Familiarity" $(F(4,35)=2.170, p=0.093)$, and "Consistency" $(\mathrm{F}(4,35)=2.869, \mathrm{p}=0.04)$. Only significant results are shown in the ANOVA Table 11.

Table 11: ANOVA results for question 2.1.2 and learnability

ANOVA- Question 2.1.2 and different sections of learnability

\begin{tabular}{llrrrrr}
\hline \hline & & Sum of & & & & \\
& & Squares & df & Mean Square & F & Sig. \\
\hline Ease of & Between Groups & 5.935 & 4 & 1.484 & 3.943 & .010 \\
learning & Within Groups & 13.169 & 35 & .376 & & \\
& Total & 19.104 & 39 & & & .093 \\
\hline Familiarity & Between Groups & 6.017 & 4 & 1.504 & 2.170 & .037 \\
& Within Groups & 24.258 & 35 & .693 & & \\
& Total & 30.275 & 39 & & & \\
\hline Consistency & Between Groups & 5.501 & 4 & 1.375 & 2.869 & \\
& Within Groups & 16.774 & 35 & .479 & & \\
& Total & 22.275 & 39 & & & \\
\hline \hline
\end{tabular}

Question 2.2.1 “The use of CASE tool enabled me to complete my tasks more quickly”

Significant differences were found for 2.2.1 on the mean overall rating for the sections "Familiarity" $(\mathrm{F}(4,35)=3.362, \mathrm{p}=0.02)$ and "Consistency" $(\mathrm{F}(4,35)=3.281, \mathrm{p}=0.02)$ (see Table 12$)$. 
Table 12: ANOVA for question 2.2.1 and learnability

ANOVA-Question 2.2.1 on learnability categories

\begin{tabular}{llrrrrr}
\hline \hline & & Sum of & & & & \\
& & Squares & df & Mean Square & F & Sig. \\
\hline Familiarity & Between Groups & 8.403 & 4 & 2.101 & 3.362 & .020 \\
& Within Groups & 21.872 & 35 & .625 & & \\
& Total & 30.275 & 39 & & & .022 \\
\hline Consistency & Between Groups & 6.075 & 4 & 1.519 & 3.281 & \\
& Within Groups & 16.200 & 35 & .463 & & \\
& Total & 22.275 & 39 & & & \\
& & & & & & \\
\hline \hline
\end{tabular}

Question 2.2.2 "The CASE tool helped me to understand the underlying concepts better"

Significant differences were also found for Question 2.2.2 on the mean overall rating for the "Familiarity" $(\mathrm{F}(4,35)=2.991, \mathrm{p}=0.03)$ (See Table 13).

Table 13: question 2.2.2 and learnability

ANOVA- Question 2.2.2 on learnability categories

\begin{tabular}{|c|c|c|c|c|c|c|}
\hline & & $\begin{array}{l}\text { Sum of } \\
\text { Squares }\end{array}$ & df & Mean Square & $\mathrm{F}$ & Sig. \\
\hline \multirow[t]{3}{*}{ Familiairty } & Between Groups & 7.712 & 4 & 1.928 & 2.991 & .032 \\
\hline & Within Groups & 22.563 & 35 & .645 & & \\
\hline & Total & 30.275 & 39 & & & \\
\hline
\end{tabular}

Question 2.2.3 "I believed that correct understanding and use of the tool would help me to perform better in the course assessments"

Significant differences were also found for Question 2.2.3 on the mean overall rating for the "Familiarity" $(\mathrm{F}(4,35)=2.88, \mathrm{p}<0.05)$ and "Predictability" $(\mathrm{F}(4,35)=2.89, \mathrm{p}<0.05)$ (see Table 14).

Table 14: question 2.2.3 and learnability

ANOVA-Question 2.2.3 on learnability categories

\begin{tabular}{llrrrrr}
\hline \hline & \multicolumn{1}{c}{ Sum of } & & & & & \\
& & Squares & df & Mean Square & F & Sig. \\
\hline Familiarity & Between Groups & 7.495 & 4 & 1.874 & 2.879 & .037 \\
& Within Groups & 22.780 & 35 & .651 & & \\
& Total & 30.275 & 39 & & & .036 \\
\hline Predictability & Between Groups & 3.643 & 4 & .911 & 2.884 & \\
& Within Groups & 11.051 & 35 & .316 & & \\
& Total & 14.694 & 39 & & & \\
& & &
\end{tabular}


Follow-up tests conducted to evaluate pairwise differences among the means did not return any results, as there were groups with fewer than 2 cases. It should be recalled that attitude and motivation was measured using a set of question on a 1-5 scale, which implies that there were five groups.

However, based on the above findings, it is implied that the learnability ratings differed significantly between students who belonged to different attitude and motivation groups.

\section{Qualitative Results}

In addition to the closed-ended questions which provided quantitative data, the qualitative data collected by the open-ended items in the questionnaire provided interesting results.

Firstly, students were asked to identify and comment about the most useful method/s that supported them in their learning of the CASE tool. The following question was included under the 'Other Information' section in the learnability questionnaire.

A range of teaching methods and resources were used to teach the CASE tool for the course. These included the textbook, weekly lab tutorials and assignments etc. These were aimed at helping you to learn the CASE tool better. What method/s were most helpful in learning the CASE tool and why?

Out of the 40 students who participated in the research, 28 students (70\%) said the weekly lab tutorials helped them the most in learning the CASE tool. Out of these 28 students, 14 also chose assignments and 5 of them said the textbook was useful. The textbooks prescribed for the course were: Dennis, Wixom and Tegarden (2003) Systems Analysis and Design: An Object Oriented Approach with UML, John Wiley \& Sons and Liew and White (2002) Data Modelling - The Foundation of Information Systems ( $3^{\text {rd }}$ edition).

Some of the comments made by students who chose weekly tutorials are given below:

"because we get a first hand experience at using the tool. And I learn something better by actually doing it”

"hands on demonstration made it very easy to use CASE tool by myself"

"easy to learn and understand since help is provided"

"could learn to use software practically"

"the tutors explained how to use the tools.. and had time to practice using it"

"learning by example"

"tutor guided learning and clarified doubts"

"very useful.. face to face help from tutors, step by step verbal instructions was very helpful in learning to use the tool"

Students who found assignments helped them in learning the CASE tool quoted the following reasons:

"get to practice more with them at liberty to try more functions"

"can use the tool for an actual purpose"

"most useful for application of the tool"

"no dilly-dallying-includes what we actually need to know" 
Most of the students felt that the Dennis, Wixom and Tegarden textbook Systems Analysis and Design: An Object Oriented Approach with UML did not help them in learning the CASE tool. It should be noted that the main goal for using the textbook for the course was to support students in better understanding of the fundamental concepts and issues related to Systems Analysis and Design using UML. The textbook does not deal with any particular CASE tool in detail. However, the 5 students who chose textbook said it helped them to understand the underlying theoretical concepts better. This might be attributed to the fact that a better understanding of the methodology might have supported the students who had read the book, in learning the tool.

\section{Comments}

The next approach to the analysis of the learnability questionnaire is the inspection of comments from students. The comments chosen and listed below represent the views and complaints of many students. They mainly belonged to the categories: 'Ease of learning', 'Familiarity' and 'Error Messages’. A brief description is provided after every comment.

\section{Ease of learning}

"its easy to learn how to use it first ..."

"definitely needed the tutorial to get the hang of using Rational Rose"

"the tool is pretty straight forward to learn and interesting"

"rose was fine as long as I don't touch the advanced parts"

Comments made about 'Ease of learning' were consistent, in terms of Rational Rose being easy to learn and get started. This was also evident from the results of the statistical analysis, where the question "It was easy for me to get started and to learn how to use the tool" was the highest rated question. However, it should be mentioned that the weekly tutorials might have played a significant role in their satisfaction ratings of some of these learnability categories.

\section{Familiarity}

"Similar, but more enhanced and complicated".

"similar functionality with the drag and drop and writing text in diagrams"

People with previous experience with computers in general and CASE tools in particular, experienced similar functionality while using the tool and found it much easier to learn than students with no prior experience. Statistically significant differences were also found to support these findings.

\section{Error Messages}

"they use jargon in error messages that I don't always understand"

"when deleting stuff from diagram- doesn't delete from left panel”

Complaints about the error messages were the most frequently reported, stating that the problems with error messages and their interpretation affected their easy learning of the tool. This is well supported by the fact that all the lowest rated questions in the learnability questionnaire belonged to the Error Messages category.

\section{Discussion}

The study has revealed that the framework can be successfully applied for the evaluation of CASE tool learnability. The effect of contextual factors such as user characteristics, the learning 
environment and the teaching and learning methodologies on learnability has been studied. It is evident from the analysis that the learning environment had an effect on learnability. Especially, the tutorial sessions and the teaching methods (demonstrations, step-by-step instructions) used in these sessions, was strongly endorsed by students as 'very helpful' in learning Rational Rose.

In general, the students found Rational Rose easy to learn and rated positively. The positive and favorable ratings could be attributed to the fact, that the students received a greater amount of guidance in getting started with the CASE tool, by means of demonstrations and tutorials in the weekly laboratory sessions. As discussed earlier, $70 \%$ of the participant students said the laboratory sessions helped them most in learning the CASE tool.

Most students generally rated the questionnaire items for 'error messages' category low and negative, and found them to be confusing and inconsistent. Some students made negative comments about Error Messages under the 'consistency' section as well. This implies that the feedback provided might not have been consistent or informative, which could have confused students. It could also be attributed to the fact that students generally do not spend enough time learning a new tool outside the scheduled class time, unless they are very close to the assignment deadlines. People usually get frustrated when they are pressurized by time and things do not work as anticipated. However, it is also an implication for improvement in tool design, to incorporate and encourage learning for novice users in educational environments.

The assignment requirements were quite specific and identified the subset of diagrams that were required to complete the tasks. This was further supported by the demonstrations in the tutorial sessions, where the tutors used the CASE tool along with suitable examples to demonstrate the creation of the diagrams that were pertinent to the course. This suggests that identification of specific set of UML diagrams might have made the learning tasks using the CASE tool much easier and affected their learnability ratings.

The effects of three user characteristics on learnability are reflected in the differences among different types of users in their mean ratings. The major findings of the study are the differences between groups of students who had different levels of both general computer experience and previous experience with CASE tools. Specifically, differences were found for the categories 'Ease of learning', 'Consistency' and 'Familiarity'. This might be attributed to the fact that users generally tend to utilize their experience when they are trying to learn a new concept or tool, during which they encounter familiar constructs and functions, which may support in their learning process. For example, Agarwal, Sinha, and Tanniru (1996) found that subjects who had previous experience in process modelling found it easier to model behaviour. In another study, Kline and Seffah (2002) found that experienced developers reported greater overall satisfaction with the CASE tool for $\mathrm{C}++$ than inexperienced developers. In general, students who had a moderate level of previous experience found the CASE tool much easier to learn, familiar and consistent.

Significant differences were also found for the characteristic 'attitude and motivation' on the learnability ratings for the categories 'Ease of learning', 'Consistency' and 'Familiarity'. This is most likely due to the fact that users who have positive attitude and are motivated, tend to be more enthusiastic towards using and learning a new tool or technology. This attitude usually implies spending more time in exploring the various functions and features of the tool, which might lead to a better understanding and satisfaction.

However, it should be mentioned that the student ratings are based mainly on their experience while learning to create fundamental diagrams such as Use Case and Activity diagrams using Rational Rose. 


\section{Implications}

Based on the analysis of the results obtained from multiple data collection methods (quantitative, qualitative and observations), the following implications are drawn:

\section{Implications for learnability research in educational environments}

Understanding the significance of context has been an important area of research in Usability studies. The findings of this research enrich our knowledge about context in the evaluation of CASE tool learnability, particularly in educational environments. The significance of the educational context recognized in the framework stems from the following facts:

Evaluating CASE tool learnability in educational environments is different from industrial environments. This is because students have different characteristics, come from varying backgrounds, and use CASE tools for different reasons with different skills and motivations. While the use of CASE tools in the industry might be to increase productivity or perform tasks more efficiently and effectively (Nielsen, 1993), in educational environments CASE tools are mainly used to 1) help students in developing the practical skills required to use and learn the underlying concepts and techniques and 2) enable the learner to focus on the more creative aspects of software development (Mynatt \& Leventhal, 1990).

The context-specific data obtained using multiple data collection methods could be combined with more focused results from on-site videotaping or observing learnability problems within the different interactions that occur in a real setting such as user-tool interactions and user-task interactions (Bourges-Waldegg, Moreno, \& Rojano, 2000), to improve the validity and relevance of case study research.

Students view complexity from different views: problem domain complexity, method or technique complexity and tool complexity (Boloix \& Robillard, 1998). The current research included the evaluation of CASE tool functionality, but the complexities of the methodology and task were not considered. Also, the amount of tool knowledge experienced by students was limited and restricted only to the development of fundamental diagrams. Further research is required to study the association between task and methodology complexities on CASE tool learnability.

\section{Implications for improvement in tool design}

One of the major findings of this study is related to the 'Error handling' capabilities of Rational Rose, which were perceived and rated very unfavorably. This was evident both from the lower user satisfaction ratings and also from the analysis of the qualitative data in both the cases. Though there were comments made in other sections such as 'Consistency' and 'Feedback', in general most of them related to 'error handling' such as, not consistent and not providing appropriate feedback when handling error messages. The problems related to error handling are widely recognized and discussed in the general field of usability research (Nielsen, 1993; Preece, Rogers \& Sharp, 2002; Seffah \& Rilling, 2001). Preventing error messages in the first place is considered as an important implication for tool design, even better than providing simple and clear messages (Preece et al., 2002; Seffah \& Rilling, 2001). The presence of appropriate and relevant feedback, specifically in the context of handling error messages, is considered to have a significant effect on the learnability and understandability of a system (Jankowski, 1995; Norman, 1999).

Problems associated with error messages are explained by using the concept of "conceptual gaps", where a conceptual gap is defined as the difference between the user's mental model of the application and how the application actually works (Seffah \& Rilling, 2001). One of the important design principles suggested by Norman (1999) which has the potential to reduce the conceptual gaps and make it easier to use and learn is the concept of 'perceived affordance'. According to Norman (1999), perceived affordance is the characteristic of a system that gives clues of how it 
can be used. The notion of perceived affordance is widely recognized by the user interface design research community (Amant, 1999; Norman, 1999), where it is believed that "perceived affordances can directly influence usability, reduce the need for instructions, user manuals, online help and support, and can also promote familiarity with the interface" (Seffah \& Rilling, 2001).

The other important finding from the study is that, most students did not use the On-line Help facility of Rational Rose. This is paradoxical as On-line help is the one resource which is readily available, especially in today's academic environments where it is accessible on most universities' site-licensed computers. A number of reasons could be attributed to the non-use of On-line Help systems. The time constraints under which students tend to learn the tool may discourage them from using on-line help. Other reasons include the weakness of on-line help systems in general, such as help window obscuring the task window, cognitive load and interruption and inability for some students to try things out and use the On-line help concurrently (Reiman, 1996).

\section{Conclusions}

The evaluation framework for CASE tool learnability that recognizes the significance of context has been derived, applied and tested in an undergraduate one-semester Systems Analysis and Design course. The framework was used as an initial guide to test the overall design and the associated questions in the learnability questionnaire.

The study investigated the effects of user characteristics on users' satisfaction ratings of CASE tool learnability. The different user characteristics used in this research included age, gender, computer experience, previous experience with CASE tools, and attitude and motivation. The learnability criteria were elicited from the usability literature, and were represented by a set of questions. Except for the 'On-line help' criteria (most students did not complete the questions under this category, which implied that they did not use On-line help) there was no evidence that any of the other features chosen to represent learnability were invalid. The inclusion of the Online Help category as a supplementary principle that supports learnability needs to be validated by further application of the framework to more cases. Some of the questions in the learnability questionnaire were found redundant and ambiguous, which might have confused some students.

The contextual factors chosen for the study, especially the learning environment and the teaching and learning methodologies and their impact on CASE tool learnability provided valuable insights. Further validation of the framework by its application to different educational contexts is implied to generalize the results. For example, application of the framework to educational contexts that use different CASE tools might provide insights for comparing the learnability features of different CASE tools. The generalizability of the questionnaire can also be established by using it for different population of users to evaluate different types of CASE tools (Chin et al., 1988).

\section{References}

Amant, R. (1999). User interface affordances in a planning representation. Human Computer Interaction, 14(3), 317-354.

Agarwal, R., Sinha, A. P., \& Tanniru, M. (1996). Cognitive fit in requirements modeling: A study of object and process methodologies. Journal of Management Information Systems, 13(2), 137-162.

Banker, R. D. \& Kauffman, R. J. (1991). Reuse and productivity in integrated computer-aided software engineering. MIS Quarterly, 15(3), 375-401.

Bevan, N. \& Macleod, M. (1994). Usability measurement in context. Behaviour and Information Technology, 13, 132-145. 
Boloix, G. \& Robillard, P. N. (1998). Case tool learnability in a software engineering course. IEEE Transactions on Education, 41(3), 185-193.

Bourges-Waldegg, P., Moreno, L. \& Rojano, T. (2000). The role of usability on the implementation and evaluation of educational technology. Proceedings of the 33rd Hawaii International Conference on System Sciences.

Burton, P. J. \& Bruhn, R. E. (2003). Using UML to facilitate the teaching of object-oriented systems analysis and design. CCSC, Southeastern Conference: Consortium for Computing Sciences in Colleges.

Chin, J. P., Diehl, V. A. \& Norman, K. L. (1988). Development of an instrument measuring user satisfaction of the human-computer interface. Proceedings of SIGCHI'88, New York, ACM/SIGCHI.

Cifuentes, C. \& Lockwood, C. (1996). Introduction of a case tool to teach structured analysis. Computers Education, 27(3/4), 197-204.

Costain, G. (1996). A framework for post-implementation review of case methodology. MCom Thesis, MSIS. Auckland, University of Auckland.

Cowling, A. J. (1998). The role of systems analysis techniques in teaching software engineering. CSEET'98, 11th conference on Software Engineering Education and Training, Atlanta, GA.

Dix, A., Abowd, G., Beale, R. \& Finlay, J. (1998). Human-computer interaction. Prentice Hall, Europe.

Finlay, P. N. \& Mitchell, A. C. (1994). Perceptions of the benefits from the introduction of case: An empirical study. MIS Quarterly, 353-370.

Fowler, L., Armarego, J. \& Allen, M. (2001). Case tools: Constructivism and its application to learning and usability of software engineering tools. Computer Science Education, 11(3), 261-272.

Frosch-Wilke, D. (2003). Using UML in software requirements analysis- Experiences from practical student project work. InSITE- Informing Science and IT Education Conference, Finland.

Galitz, W. O. (1996). The essential guide to user interface design. Wiley Computer Publishing.

Holt, J. D. (1997). Current practice in software engineering-a survey. Computing and Control Engineering Journal, 8, 167-172.

Jankowski, D. J. (1995). Case feedback in support of learning a systems development methodology. Journal of Information Systems Education, 7(3), 88-90.

Jones, A., Scanlon, E., Tosunoglu, C., Morris, E., Ross, S., Butcher, P. \& Greenberg, J. (1999). Contexts for evaluating educational software. Interacting with Computers, 11, 499-516.

Johnson, H. A. \& Wilkinson, L. (2003). Case tools in object-oriented analysis and design. Eastern Conference: Consortium for Computing Services in Colleges.

Kline, A. \& Seffah, A. (2002). Empirical study of software developers' experiences. WESS'02 Eighth IEEE workshop on empirical studies of software maintenance, Montreal,Quebec,Canada.

Linder, N., Steele, P., \& Dorling, R. (1994). Using a commercial integrated case tool in an undergraduate computing degree. Proceedings of the Software Education Conference, 22- 25 Nov, 1994, 212-218.

Misra, S. K. (1990). Analysing case system characteristics: Evaluative framework. Information and Software Technology, 32(6), 415-422.

Mosley, V. (1992). How to assess tools efficiently and quantitatively. IEEE Software, 9(3), 29-32.

Mynatt, B. T. \& Leventhal, L. M. (1989). A case primer for computer science educators. Proceedings of the $20^{\text {th }}$ SIFCSE technical symposium on Computer Science Education, Kentucky, United States, 122-126.

Mynatt, B. T. \& Leventhal, L. M. (1990). An evaluation of a case-based approach to teaching undergrdautae software engineering. Proceedings of the $21^{\text {st }}$ h SIFCSE technical symposium on Computer Science Education, Washington, DC, United States, 48-52.

Nielsen, J. (1993). Usability engineering. Academim Press. 
Norman, D. A. (1999). Affordance, conventions and design. SIGCHI Interactions, 6(3), 38-42.

Phillips, C., Mehandjiska, D., Griffin, D., Choi, M. D., Page, D. (1998). The usability component of a framework for the evaluation of $\mathrm{OO}$ case tools. Proceedings of Software Engineering, Education and Practice, IEEE, Dunedin.

Preece, J. (1993). A guide to usability: Human factors in computing. Addison Wesley.

Preece, J., Rogers, Y., \& Sharp, H. (2002). Interaction design: Beyond human-computer interaction. USA: John Wiley \& Sons.

Rajkumar, T. M. (1992). Incorporating case in the systems analysis and design course. Journal of Information Systems Education, 4(4).

Rieman, J. (1996). A field of exploratory learning strategies. ACM Transactions on Computer-Human Interaction, 3(3), 189-218.

Seffah, A. \& Rilling, J. (2001). Investigating the relationship between usability and conceptual gaps of human-centric case tools. IEEE Software, 226-231.

Shneiderman, B. (1992). Designing the user interface: Strategies for effective human computer interaction. Reading, MA: Addison Wesley.

Shneiderman, B. (1998). Designing the user interface: Strategies for effective human-computer interaction. Addison-Wesley.

Squires, D. \& Preece, J. (1996). Usability and learning: Evaluating the potential of educational software. Computers Education, 27(1), 15-22.

Tabrizi, M. H. N., Collins, C., Ozan, E. \& Li, K. (2004). Implementation of object-orientation using UML in entry level software development courses. SIGITE'04, Salt Lake City, Utah, USA.

\section{Biography}

Mali Senapathi is a Senior lecturer in the School of Computer and Information Sciences, Auckland University of Technology, New Zealand. She has been lecturing and developing course content in systems analysis and design and data base management systems since 1999. Her research interests include IT education and software usability. 